\title{
Fiction From a Critical Perspective
}

\author{
Suhair Al-Alami \\ Al Ghurair University, Dubai, UAE
}

\begin{abstract}
With English as a lingua franca in mind, it has become essential for undergraduate students to acquire the English language. Additionally, undergraduate students are expected to acquire a repertoire of critical thinking skills for lifelong learning. Inspired by the need to augment mastery of English as a foreign language (EFL) whilst at the same time enhancing critical thinking on the part of EFL learners, the research study this paper portrays was conducted for one academic semester involving a number of students at the institution where the author of this paper works. The research aimed to investigate whether using English novels; novellas; and short stories for teaching purposes would have any significant impacts on subjects' attitudes towards using literary texts for enhancement of both critical thinking and EFL skills. To achieve the intended aim, the researcher used eight English short stories and one novella in class besides assigning one English novel as extensive reading, while teaching the course Communication Skills during the implementation stage. The researcher also administered a pre-post questionnaire with the aim of measuring subjects' attitudes towards utilizing novels; novellas; and short stories as a means for fostering both critical thinking and EFL skills. Based on the statistical tests, there were significant differences in favor of the post questionnaire regarding the majority of the questionnaire's items. Based on this study, it can be concluded that English novels; novellas; and short stories have a significant role to play in relation to developing critical thinking and EFL skills.
\end{abstract}

Index Terms - critical thinking, EFL, higher education, novel, novella, short story

\section{INTRODUCTION}

With today's challenges in mind, undergraduates should embrace the four Cs: critical thinking, communication, creativity, and collaboration (Al-Alami, 2016). Commenting on critical thinking in particular, it goes without saying that critical thinking skills are essential for university students to be able to cope with today's rapidly increasing demands with tenacity and professionalism.

Critical thinking is required for literature studies. Novel reading, for instance, involves retrieving one's prior experiences to construct meaning. As students read a novel, they need to understand both connotations and denotations, comprehend the literal and implied meanings, recognize the narrator's tone and attitude, and deduce meaning of unfamiliar lexical items. Moreover, students need to discriminate between facts and opinions, locate appropriate details to find connections between events and actions, identify literary devices, perceive multiple points of view, and appreciate beauty depicted in content and reflected in language.

Inspired by the significant role novels, novellas, and short stories can play in terms of enhancing undergraduates' critical thinking and language skills, the current paper portrays a research study which was conducted at a private university in Dubai where English is taught as a foreign language. The second section of the paper presents the study's aims and questions. The third section sheds light on some relevant points in relation to the current study such as activities for developing critical thinking via utilizing novels, novellas, and short stories. The fourth section explains the methodology employed while conducting the study, the fifth highlights the study findings, and the sixth proceeds to discuss the findings. The last section concludes with recommendations for researchers and instructors to consider.

\section{RESEARCH AIMS AND QUESTIONS}

The current paper discusses a research study which was conducted within the contexts of English as a foreign language (EFL) in Higher Education. The study was intended to measure EFL undergraduates' attitudes towards the role novels, novellas, and short stories could occupy as regards boosting critical thinking skills and increasing mastery of English as a foreign language. To realize the intended aims, the study sought answers to the three research questions below.

Question One: What are EFL undergraduates' attitudes towards the role novels, novellas and short stories play in relation to enhancing critical thinking skills?

Question Two: What are EFL undergraduates' attitudes towards the role novels, novellas and short stories have in relation to promoting the skill of reading in a foreign language?

Question Three: What are EFL undergraduates' attitudes towards the role novels, novellas and short stories occupy in relation to boosting the skill of writing in a foreign language?

\section{LITERATURE REVIEW}


This section aims to explore several areas of relevance and use to the current paper. These are: critical thinking skills, reading and writing critically, related studies, and activities for developing EFL undergraduates' critical reading and writing skills via utilizing novels; novellas; and short stories within the contexts of Higher Education.

\section{A. Critical Thinking at a Glance}

Critical thinking can be defined as having sufficient awareness of one's own thinking and reflecting on the thinking of the self and others (Semerci \& Elaldi, 2014). The difference between thinking and critical thinking is similar to the difference between walking and dancing in that whereas the former is learned naturally during the course of a kid's early-life period of time, the latter necessitates effort to learn (Gelder, 2005; Ritchart \& Perkins, 2005). According to Kutz et al. (1993), students need several types of critical thinking to enrich their knowledge. One necessary type is 'dialectical' which would enable students to accept ambiguity and value dialogue. A second essential type is 'analytic' which would enable students to analyze topics and issues in terms of their categories and the implications they hold. A third important type is 'figurative' which would enable students to view events and things as pointing to something else.

As seen by the author of this paper, critical thinking entails seeing beyond visible matters and issues, whilst investigating seen and hidden intents. It requires gathering relevant data and assessing the gathered data in terms of validity, reliability, authority, and credibility. The concept of critical thinking comprises dispositions and higher order thinking skills. Dispositions can be considered habits of mind and attitudes including willingness to compromise, openmindedness, flexibility, and respect for diverse opinions amongst other characteristics. Higher order thinking skills, on the other hand, include the ability to make inferences, use deductive and inductive reasoning, judge evidence, solve problems, make objective decisions, and evaluate complex arguments amongst other skills.

\section{B. Reading and Writing Critically in the EFL Literature Class}

EFL classes do not usually aim to prioritize the enhancement of critical thinking. However, the integration of critical thinking with language skills such as reading and writing should receive more attention (Kagnarith, Theara \& Klein, 2007). What does critical reading within EFL contexts require? In Wallace's view (2003), critical reading entails exploring the topic a reading text deals with, whilst adopting an attitude of inquiry and examination. Wallace suggests a framework for critical reading relying on the tenor, area, and mode of discourse. Relating the discussion to genre type, critical reading involves analyzing genre-related conventions in a text. Genre conventions exist not only at the level of individual sentences, but also at the level of both overall schemas and ideas (Durant et al., 2000). Dooley (1993) is of the opinion that critical reading comprises both analysis and evaluation prior to, during, and following reading. To be a critical reader, a student is expected to judge the authenticity, validity, and reliability of reading texts.

As far as critical writing within EFL contexts is concerned, it can be demanding for a number of learners. Nevertheless, it should be the instructor's mission to overcome obstacles through means of effective teaching amongst others. Critical writing courses involve students in the kinds of tasks that would urge them to make valid judgements. While teaching critical writing, evaluating issues and topics from a critical perspective would be essential. When considered from a critical perspective, classroom assignments should seek to highlight the transmission of relationships; ideologies; and identities as means for supporting students to make choices throughout the writing process whilst reflecting on what they do and who they aim to be (Paltridge, 2004). Bell (1995) advocates the idea that in a writing classroom which employs a critical theory, teaching and learning are regarded as constructs: rhetorical and often oppressive representations of social relationships. Students should examine implicit constructs within their environments which may be demanding as it necessitates effective involvement in exploring what does not necessarily fit into the 'product-oriented' instructional settings which students are familiar with.

In sum, both critical reading and critical writing are comprised of several skills such as text reasoning, inferencing, and problem-solving amongst others. Critical reading of novels; novellas; and short stories is an advanced stage of reading comprehension during which readers read between and behind the lines, avoiding literal interpretations. Critical writing of novels; novellas; and short stories, on the other hand, is a reflection of a potent language style worthy of readers' aesthetic appreciation. Undoubtedly, EFL undergraduates cannot read and write critically in the absence of adequate background knowledge about key concepts.

\section{Research Studies}

This part highlights several studies which have been implemented with the aim of augmenting critical thinking and language skills, mainly via novels; novellas; and short stories within EFL Higher Education contexts. To start with, Wiboonwachara (2019) measured the effect of question-based activities on students' critical thinking skills alongside the subjects' opinions of the question-based activities. A sample of forty-three second-year students majoring in English participated in the study. The study findings indicated that the critical thinking skills of subjects became higher after the implementation of the study at 0.05 level of significance. Furthermore, the subjects' opinions of question-based activities were also higher following the implementation of the study. The subjects became better aware of questioning in both academic and life situation contexts.

Tosuncuoglu (2018) applied a study with the aim of measuring participants' perceptions of critical thinking subdimensions, involving two hundred and twenty-two students at Karabuk University. The study results in relation to the variable of gender proved that there was no significant difference among the sub-dimensions of flexibility, 
perseverance-patience, open-mindedness, and meta-cognition. The study results also showed that senior-year subjects had more patience and perseverance in comparison to sophomore-year subjects with respect to the sub-dimension of perseverance-patience, indicating that subjects gained more patience and perseverance when the study level had become higher.

Yang and Gamble (2013) designed a study where two groups: experimental and control, were involved. Experimental group students were engaged in critical thinking enhanced activities like peer critiques, whereas control group students were engaged in non-critical thinking enhanced activities. The findings revealed that experimental group students achieved a significant improvement in relation to English language proficiency when compared to the control group students.

Beachboard and Beachboard (2010) investigated the relationship between the assignment of higher order thinking tasks and students' opinions of their institutions' contributions to their academic improvement and career preparation. The results showed that the extra effort made by faculty members to involve their students in higher order thinking assignments made a difference in relation to the enhancement of critical thinking skills.

In their study, Tung and Chang (2009) explored whether literature would help weak thinkers to improve their critical thinking. The results demonstrated that literature played a positive role in helping weak students to enhance their critical thinking skills. Tung and Chang, therefore, recommend that more time be allocated for weak students to challenge their ideas at a deeper level. Additionally, group presentations should be used, and follow-up courses need to be designed in order for students to promote their critical thinking skills whilst reading literature.

Barry and Lazarte (1998) tested how domain knowledge, reading topic, and structural complexity affected the inference skill in relation to students' writing. Three types of inferences were examined: within-text inferences, elaborative inferences, and incorrect inferences. The two participating groups: high-knowledge and low-knowledge, were presented with three Spanish texts about different topics and of different language complexity levels. The findings showed that the group including high-knowledge readers could generate a more accurate mental model than the group including low-knowledge readers could. In addition, the level of complexity and the reading topics indicated a complex pattern of influence on the generation of inferences.

Involving a number of community college students, Manning (1997) explored the relationship between students' attitudes towards reading and critical thinking. The study included two sections: one was taught the regular curriculum and the other the regular curriculum besides pedagogical activities which focused on critical thinking. The results proved the absence of any statistically significant correlations between the two groups' attitudes towards reading and critical thinking.

In conclusion, the aforementioned studies can be of use to EFL researchers in the sense that they touch upon reality, probing and proposing. Resorting to what previous researchers have applied and recommended would remain informative and enlightening.

\section{Proposed Activities and Ideas for Enhancement of Critical Thinking via Novels, Novellas, and Short Stories}

This part highlights some activities and ideas the aim of which is to upgrade critical thinking skills mostly via means of novels; novellas; and short stories. To begin, Tosuncuoglu (2018) argues that students should be explicitly taught how to think critically. Thinking critically is a combination of knowledge, skill, and attitude. The more practice in how to think critically, the better the output. Instructors, therefore, need to provide a stimulating learning environment where students can express their thoughts flexibly. Among the strategies that can be employed are ensuring versatile perspective, raising questions, and working collaboratively.

Critical discourse analysis considers discourse as a means of social practices where language use is seen as socially influential and influenced. The critical discourse approach to literature and language studies prioritizes the development of students' abilities to judge the world thoughtfully as well as to change it if possible (Zyngier and Fialho, 2010; Cots, 2006)., students need to receive training activities as regards how to judge the world around them carefully.

Hyatt (2005) introduces a critical literacy frame, allowing analysis of text from a macro semantic and societal level and a micro lexico-grammatical level. On the other hand, Na and Kim (2003) portray how critical literacy is concerned with issues such as critical awareness and empowerment in foreign language education and propose an instructional framework for empowerment of EFL students. Adopting a critical literacy frame is expected to enhance EFL educational practices within the following areas: raising awareness about how to reflect critically on the world and the word, and empowering students via means of challenging unequal power relations amongst others.

Pike-Paky (2005) asserts that schema theories occupy the center of the current understanding of cognition in that schemas receive, sort, and classify information. To be in an appropriate position to fill in schema gaps, instructors have to know each and every student so that they can design a variety of appropriate activities to meet students' learning styles. A "say, mean, matter" strategy can be applied to enhance critical thinking skills via literature. Activities based on this strategy are a three-column chart with the three headings: say, mean, and matter.

In Pierce's opinion (2005), instructors aiming to augment students' critical thinking skills should focus on creating a class environment which emphasizes speculation and questioning strategies and should utilize tasks which require analyzing content whilst at the same time developing learners' oral and written language skills. Esplugas and Landwehr (1996), on the other hand, argue that in an engaging literature class, students learn how to discuss their interpretations of 
literary texts and how to also offer well-reasoned arguments. Through character, theme and narrator analyses, an instructor should ensure integrating critical thinking skills into literary analyses of a literary work.

Literature instruction, Collins (1993) states, should be looked at from a problem-solving perspective whereby students are required to draw conclusions, evaluate evidence, and develop a line of thinking. To become critical thinkers, students should learn how to value their own thinking as well as others'. Seeking to foster critical thinking skills on the part of learners, Commeyras (1993) proposes a critical-thinking reading lesson format to be implemented when discussing stories in the basal reader: a dialogical-thinking reading lesson (DTRL). The format is intended to involve students in reflective thinking activities to convey their opinions regarding a story's specific issues.

According to the author of this paper, activities which aim to develop critical thinking via novels; novellas; and short stories should be of inspiration to students. Within the context of EFL in higher education, the author proposes adopting a six-W model while portraying a literary text: who, whom, what, why, where, and when. EFL instructors should also implement a seven-step reading approach when delineating novels; novellas; and short stories: comprehend the text's gist, analyze main ideas, interpret beliefs and occurrences, infer information implicitly conveyed, draw conclusions, assess attitudes, and evaluate language use. To augment critical thinking skills while discussing novels; novellas; and short stories, the author recommends including essential elements of critical thinking activities such as raising intriguing questions, welcoming divergent answers which are backed up with proof, encouraging answers which are supported with relevant data, and providing chances to judge evidence. Logically speaking, the responsibility of creating critical thinking atmospheres in the EFL literature classroom highly falls on instructors' shoulders. Moreover, the more meaningful practices students are exposed to, the more they are likely to master critical thinking skills which would ultimately equip them with varied tools to encounter today's challenges with confidence and persistence.

\section{RESEARCH METHODOLOGY}

Comprised of four parts, this section of the current paper delineates the research methodology employed for the purpose of arriving at transparent answers to the research questions this study addresses.

\section{A. Population and Sample}

The study population includes EFL undergraduates majoring in programs other than English language and literature. As we cannot examine the whole research population due to practicality reasons amongst others, we should be wisely selective when it comes to choosing a study sample. Regarding the research the current paper presents, the study sample is a number of EFL students studying at the university where the researcher works. The sample includes both male and female students and covers the colleges whose medium of instruction is English: Business Studies, Engineering, and Interior Design. The total number of the sample is fifteen students.

\section{B. Implementation}

Since the main goal of teaching EFL is for learners to communicate in English fluently, accurately and appropriately in stretches of spoken and written discourse, the researcher selected the course Communication Skills for applying this research study. The implementation stage was limited to one academic semester, namely fifteen weeks. The first two weeks were allotted to introducing the study and were followed by teaching eight short stories and one novella. Additionally, one novel was assigned as extensive reading. It is worth noting in this context that all the students who register for the course Communication Skills at the institution where the researcher works are taught a General English course rather than a literature-based course. For study purposes, however, the researcher did not use a General English course for teaching Communication Skills during the research conduct stage.

\section{Data Gathering Tool}

As mentioned earlier, this study sought to measure EFL undergraduates' attitudes towards the role novels, novellas, and short stories could occupy as regards boosting critical thinking skills and increasing mastery of English as a foreign language. The researcher, therefore, designed and administered a questionnaire involving the study subjects. The questionnaire was distributed prior to teaching the course Communication Skills through using novels; novellas; and short stories, and upon completion of the course to investigate whether there were any significant differences regarding subjects' attitudes. The pre-post questionnaire is comprised of fifteen items aiming to measure how study subjects would evaluate their abilities in dealing with novels; novellas; and short stories whilst considering the role fictional texts could play with respect to developing critical thinking and EFL skills. Table one below presents the pre-post questionnaire which was set and administered for study purposes. 
TABLE 1

THE PRE-POST QUESTIONNAIRE

\begin{tabular}{|c|c|c|c|c|c|c|}
\hline No. & Item & $\mathbf{0}$ & 1 & 2 & 3 & 4 \\
\hline 1. & Identifying the theme. & & & & & \\
\hline 2. & Identifying the plot. & & & & & \\
\hline 3. & Identifying the narrator's attitude and opinion. & & & & & \\
\hline 4. & Identifying the characters' attitudes and moods. & & & & & \\
\hline 5. & Recognizing variations in vocabulary according to the theme and situation. & & & & & \\
\hline 6. & Deducing the meaning of unfamiliar lexical items from context. & & & & & \\
\hline 7. & Making judgments based on personal experiences. & & & & & \\
\hline 8. & Identifying the conflict. & & & & & \\
\hline 9. & Identifying the genre. & & & & & \\
\hline 10. & Recognizing the symbolism used. & & & & & \\
\hline 11. & Recognizing the irony conveyed. & & & & & \\
\hline 12. & Appreciating the figurative language manipulated. & & & & & \\
\hline 13. & Going beyond the short story/novella/novel, predicting possible outcomes. & & & & & \\
\hline 14. & Summarizing a whole story or specific events. & & & & & \\
\hline 15. & Writing a short story, establishing an opening; characters and one or more events. & & & & & \\
\hline
\end{tabular}

\section{Ethical Considerations}

The nature of this study entailed no physical dangers or threats to the study subjects. However, the research study required that subjects study the course Communication Skills via means of literary texts (eight short stories and one novella in class besides one novel for extensive reading) rather than via the General English course used for teaching Communication Skills at the institution where the researcher works. Furthermore, the study required that participants respond objectively to the questionnaire set for study purposes. With research ethics in mind, the researcher held a session prior to study implementation, during which she discussed the study's aims and requirements in detail. Study subjects were offered the right to drop the course at any time during the academic semester whilst retaining the money they had paid for the course Communication Skills as a fee deposit. Study subjects were also offered the opportunity to remain anonymous when it came to documenting their responses to the questionnaire prior to and upon completion of the course, not to mention that their rights and opinions were respected and valued.

\section{STUdY FInDINGS}

This section of the paper is concerned with presenting research findings based on the statistical tests conducted for the sake of the current study. As stated earlier, the study tool was a pre-post questionnaire which required rating one's abilities in dealing with the short story, novella, and novel in English. To analyze the pre-post questionnaire, a paired $t$ test was conducted. Table two below portrays the results. 
TABLE 2:

SUBJECTS’ RESPONSES TO THE PRE-POST QUESTIONNAIRE PaIRED SAMPLES STATISTICS

\begin{tabular}{|c|c|c|c|c|c|}
\hline \multicolumn{2}{|c|}{ Pair } & Mean & $\mathrm{N}$ & Std. Deviation & Std. Error Mean \\
\hline \multirow{2}{*}{ Pair 1} & pr1 & 2.18 & 17 & .951 & .231 \\
\hline & po1 & 2.76 & 17 & .752 & 182 \\
\hline \multirow{2}{*}{ Pair 2} & pr2 & 2.29 & 17 & .920 & .223 \\
\hline & po2 & 2.47 & 17 & .717 & .174 \\
\hline \multirow{2}{*}{ Pair 3} & pr3 & 2.76 & 17 & .752 & 182 \\
\hline & po3 & 2.76 & 17 & .903 & 219 \\
\hline \multirow{2}{*}{ Pair 4} & pr4 & 2.47 & 17 & .874 & 212 \\
\hline & po4 & 2.94 & 17 & .827 & 201 \\
\hline \multirow{2}{*}{ Pair 5} & pr5 & 2.29 & 17 & 1.213 & .294 \\
\hline & po5 & 2.65 & 17 & .786 & .191 \\
\hline \multirow{2}{*}{ Pair 6} & pr6 & 2.06 & 16 & .854 & 213 \\
\hline & po6 & 2.38 & 16 & .957 & 239 \\
\hline \multirow{2}{*}{ Pair 7} & pr7 & 2.71 & 17 & .849 & 206 \\
\hline & po7 & 2.82 & 17 & .951 & 231 \\
\hline \multirow{2}{*}{ Pair 8} & pr8 & 2.24 & 17 & .752 & 182 \\
\hline & po8 & 2.88 & 17 & .781 & 189 \\
\hline \multirow{2}{*}{ Pair 9} & pr9 & 2.06 & 17 & 1.249 & .303 \\
\hline & po9 & 2.71 & 17 & .920 & 223 \\
\hline \multirow{2}{*}{ Pair 10} & pr10 & 1.88 & 17 & .993 & 241 \\
\hline & po10 & 2.71 & 17 & .920 & .223 \\
\hline \multirow{2}{*}{ Pair 11} & pr11 & 2.18 & 17 & 1.131 & .274 \\
\hline & po11 & 2.65 & 17 & .931 & .226 \\
\hline \multirow{2}{*}{ Pair 12} & pr12 & 2.13 & 16 & .885 & .221 \\
\hline & po12 & 2.63 & 16 & .885 & .221 \\
\hline \multirow{2}{*}{ Pair 13} & pr13 & 2.41 & 17 & .870 & 211 \\
\hline & po13 & 3.12 & 17 & .697 & 169 \\
\hline \multirow{2}{*}{ Pair 14} & pr14 & 2.41 & 17 & .870 & 211 \\
\hline & po14 & 3.00 & 17 & .791 & .192 \\
\hline \multirow{2}{*}{ Pair 15} & $\operatorname{pr} 15$ & 1.94 & 17 & 1.144 & .277 \\
\hline & po15 & 2.47 & 17 & .874 & .212 \\
\hline
\end{tabular}

\begin{tabular}{|c|c|c|c|c|c|c|c|c|c|}
\hline \multicolumn{10}{|c|}{ Paired Samples Test } \\
\hline & \multirow[t]{3}{*}{ Pair } & \multicolumn{5}{|c|}{ Paired Differences } & \multirow[t]{3}{*}{$\mathrm{t}$} & \multirow[t]{3}{*}{ Df } & \multirow[t]{3}{*}{ Sig. (2-tailed) } \\
\hline & & \multirow[t]{2}{*}{ Mean } & \multirow[t]{2}{*}{ Std. Deviation } & \multirow[t]{2}{*}{ Std. Error Mean } & \multicolumn{2}{|c|}{$\begin{array}{l}95 \% \text { Confidence Interval of the } \\
\text { Difference }\end{array}$} & & & \\
\hline & & & & & Lower & Upper & & & \\
\hline Pair 1 & pr1 - pol & -.588 & .507 & .123 & -.849 & -.327 & -4.781 & 16 & .000 \\
\hline Pair 2 & pr2 - po2 & -.176 & .529 & .128 & -.448 & .095 & -1.376 & 16 & 188 \\
\hline Pair 3 & pr3 - po3 & .000 & 612 & 149 & -.315 & .315 & .000 & 16 & 1.000 \\
\hline Pair 4 & pr4-po4 & -.471 & .717 & .174 & -.839 & -.102 & -2.704 & 16 & .016 \\
\hline Pair 5 & pr5 - po5 & -.353 & .931 & .226 & -.832 & .126 & -1.562 & 16 & .138 \\
\hline Pair 6 & pr6 - po6 & -.313 & 1.014 & .254 & -.853 & .228 & -1.232 & 15 & .237 \\
\hline Pair 7 & pr7 - po7 & -.118 & .857 & 208 & -.559 & .323 & -.566 & 16 & .579 \\
\hline Pair 8 & pr8 - po8 & -.647 & .862 & 209 & -1.090 & -.204 & -3.096 & 16 & .007 \\
\hline Pair 9 & pr9 - po9 & -.647 & 1.169 & .284 & -1.248 & -.046 & -2.281 & 16 & .037 \\
\hline Pair 10 & pr10 - po10 & -.824 & .883 & .214 & -1.277 & -.370 & -3.846 & 16 & .001 \\
\hline Pair 11 & pr11-po11 & -.471 & 624 & .151 & -.792 & -.150 & -3.108 & 16 & .007 \\
\hline Pair 12 & pr12 - po12 & -.500 & .730 & .183 & -.889 & -.111 & -2.739 & 15 & .015 \\
\hline Pair 13 & pr13 - po13 & -.706 & .985 & .239 & -1.212 & -.199 & -2.954 & 16 & .009 \\
\hline Pair 14 & pr14-po14 & -.588 & .939 & .228 & -1.071 & -.105 & -2.582 & 16 & .020 \\
\hline Pair 15 & pr15 - po15 & -.529 & .943 & 229 & -1.014 & -.044 & -2.314 & 16 & .034 \\
\hline
\end{tabular}

The p-value (Sig.) confirms the presence of significant differences between subjects' answers to the first, fourth, eighth, ninth, tenth, eleventh, twelfth, thirteenth, fourteenth, and fifteenth items before and upon course completion, in favor of the post-questionnaire's responses.

\section{Discussion OF Study Findings}

This section of the paper seeks to offer valid answers to the research questions of this study, in light of the findings provided by the statistical tests. As mentioned earlier, question one is concerned with measuring EFL undergraduates' attitudes towards the role novels; novellas; and short stories play in relation to enhancing critical thinking skills. The study findings prove that there are significant differences between subjects' responses to ten out of fifteen items in favor of the post-questionnaire. The items which are significantly different and are related to the first question are: appreciating figurative language, and going beyond the short story/novella//novel predicting possible outcomes.

Moving to question two which is concerned with measuring EFL undergraduates' attitudes towards the role novels; novellas; and short stories contribute in terms of promoting the skill of reading in a foreign language, the study findings 
indicate that there are significant differences between subjects' responses in favor of the post-questionnaire as regards the items of identifying the theme, identifying characters' attitudes and moods, identifying the conflict, identifying the genre, recognizing symbolism, and recognizing irony.

Proceeding to the third question which is concerned with measuring EFL undergraduates' attitudes towards the role novels; novellas; and short stories occupy as regards boosting the skill of writing in a foreign language, there are significant differences in favor of the post-questionnaire regarding the items of summarizing a story and writing a short story.

Based on the research findings, we can conclude that novels, novellas, and short stories can play a significant role in terms of enhancing critical thinking and increasing mastery of language skills, within EFL Higher Education contexts.

\section{CONCLUSION}

This study has three limitations. The number of participants is fifteen, the number of participating institutions is one, and the duration of course implementation is one academic semester. It is recommended that similar studies be conducted involving larger samples, more institutions, and longer durations.

A purposeful course to focus on novels; novellas; and short stories from a critical perspective should first expose students to the basic differences among paraphrasing, explicating, describing a text, and critical enquiry. The course should then expose students to a variety of criticism tools such as those of stylistics which are necessary to read and write critically. To ensure quality outcomes, criteria are required to highlight the qualities of thought learners should strive to aim for such as precision, relevance, inquisitiveness, validity, accuracy, logic, clarity, adequacy, depth, objectivity, specificity, and breadth.

To conclude, enhancing critical thinking and language skills via literature should be amongst higher education institutions' priorities, for as is known, today's critical thinkers and effective communicators are tomorrow's healthy citizens. True it is though that for higher education institutions to empower students with critical thinking skills via utilizing novels; novellas; and short stories within foreign language contexts can be demanding in several ways. Yet, if we do not experience authentic challenges throughout our journey to attain targets, hardly can we perceive the tasty seeds we plough!

\section{REFERENCES}

[1] Al-Alami, S. (2016). Literature in the EFL World: Points to Ponder. International Journal of English Language and Literature Studies, 5(3): 144-153.

[2] Barry, S. and Lazarte, A. (1998). Evidence for Mental Models. The Modern Language Journal, 82 (1): 176-193.

[3] Beachboard, M.R. and Beachboard, J.C. (2010). Critical-Thinking Pedagogy and Student Perceptions of University Contributions to Their Academic Development. Informing Science: The International Journal of an Emerging Transdiscipline, Vol. 13: 53-67.

[4] Bell, D.C. (1995). Motivation and Critical Pedagogy. Dissertation Abstracts International, 57 (6): 2395.

[5] Collins, C. (1993). Reading Instruction That Increases Thinking Abilities. Journal of Reading, 34(7): 510-516.

[6] Commeyras, M. (1993). Promoting Critical Thinking through Dialogical-Thinking Reading Lessons. The Reading Teacher, 46 (6): 486-495.

[7] Cots, J.M. (2006). Teaching with an Attitude: Critical Discourse Analysis in EFL Teaching. ELT Journal, 60 (4): $336-345$.

[8] Dooley, C. (1993). The Challenge: Meeting the Needs of Gifted Readers. The Reading Teacher, 46 (7): $446-551$.

[9] Durant, A. et al. (2000). Ways of Reading: Advanced Reading Skills for Students of English Literature ( $2^{\text {nd }}$ edition). London and New York: Routledge.

[10] Esplugas, C. and Landwehr, M. (1996). The Use of Critical Thinking Skills in Literary Analysis. Foreign Language Annals, 29 (3): 449-462.

[11] Gelder, T.V. (2005). Teaching Critical Learning: Some Lessons from Cognitive Science. College Teaching, 45 (1): 1-6.

[12] Hyatt, D. (2005). A Critical Literacy Frame for UK Secondary Education. English in Education, 39 (1): 43-59.

[13] Kagnaritch, C., Theara, C., and Klein, A. (2007). A Questionnaire Project: Integrating the Four Macro Skills with Critical Thinking. English Teaching Forum, 45 (1): 2-9.

[14] Kutz, E. et al. (1993). The Discovery of Competence. United States of America: Cook Publishers.

[15] Manning, W.J. (1997). The Relationship between Critical Thinking and Attitudes toward Reading of the Community College Student Enrolled in a Critical Reading Course at Roane State Community College. Dissertation Abstracts International, 59 (8): 2838-2839.

[16] Na, Y.H. and Kim, S.J. (2003). Critical Literacy in the EFL Classroom. English Teaching, 58 (3): 143-163.

[17] Paltridge, B. (2004). Academic Writing. Language Teaching Journal, Vol. 37: 87-105.

[18] Pierce, B. (2005). Handbook of Critical Thinking Resources. United States of America: Macmillan.

[19] Pike-Baky, M. (2005, March). Three Powerful Strategies for Developing Critical Readers. Paper presented at the TESOL Arabia Annual International Conference 2005. Dubai: Al Bustan Rotana Hotel.

[20] Ritchart, R. and Perkins, D.N. (2005). Learning to Think: The Challenges of Teaching Thinking. In Keith, J. et al. (eds.) The Cambridge Handbook of Thinking and Reasoning. United Kingdom: Cambridge University Press: 775-802.

[21] Semerci, C. and Elaldi, S. (2014). The Roles of Metacognitive Beliefs in Developing Critical Thinking Skills. Bartin University Journal of Faculty of Education, 3 (2): 317-333.

[22] Tosuncuoglu, I. (2018). English Language and Literature Students' Perceptions of Critical Thinking. International Journal of Higher Education, 7(5): 20-28. 
[23] Tung C-A. and Chang, S-Y. (2009). Developing Critical Thinking through Literature Reading. Feng China Journal of Humanities and Social Sciences, Vol. 19: 287-317.

[24] Wallace, C. (2003). Critical Reading in Language Education. United Kingdom: Palgrave Macmillan.

[25] Wiboonwachara, L. (2019). The Effects of Questioning Technique on Critical Thinking of Thai EFL Learners. The New English Teacher, 13 (2): 12-23.

[26] Yang, Y-C. and Gamble, J. (2013). Effective and Practical Thinking-Enhanced EFL Instruction. ELT Journal, 67(4): 398-412.

[27] Zyngier, S. and Fialho, O. (2010). Pedagogical Stylistics, Literary Awareness and Empowerment: A Critical Perspective. Language and Literature, 19 (1): 13-33.

Suhair Al-Alami holds a PhD in English Applied Linguistics from Aston University, United Kingdom, and a PhD in English Linguistics from Ain Shams University, Egypt. She currently works as Associate Professor of English at Al Ghurair University, Dubai. She has contributed a wide range of research papers to various international journals, served as a co-editor of eight publications, reviewed a large number of articles for refereed journals, and presented research papers at numerous conferences in nine countries. She has also received several awards for her research, teaching, professional development, and community service activities and contributions.

ORCID ID: http://orcid.org/0000-0003-1488-4305 